\title{
Physical modelling of piles under lateral loading in unsaturated soils
}

\author{
Leonardo Maria Lalicata $^{1 *}$, Giada Maria Rotisciani $^{2}$, Augusto Desideri ${ }^{2}$, Francesca Casini $^{3}$, and Luc Thorel $^{4}$ \\ ${ }^{1}$ Department of Civil Engineering, City, University of London, Northampton Square, EC1V 0HB London, UK \\ ${ }^{2}$ Department of Structural \& Geotechnical Engineering, University of Rome La Sapienza, Via Eudossiana 18 Rome, Italy \\ ${ }^{3}$ Dipartimento di Ingegneria Civile e Ingegneria Informatica, Università degli Studi di Roma "Tor Vergata", via del Politecnico 1, \\ Rome, Italy \\ ${ }^{4}$ GERS Department, Geomaterials and Modelling in Geotechnics Laboratory, IFSTTAR, Bouguenais, France
}

\begin{abstract}
In this paper, selected aspects of an experimental study conducted in a geotechnical centrifuge are discussed. The tests aimed to explore the effects of partial saturation of soil on the response of a single pile subjected to a combination of lateral force and bending moment under drained conditions. The soil used in the experiments is a low plasticity silty soil, named B-grade kaolin, characterized by a relatively high permeability compared to the typical values for clayey soils. Two different elevations of the water table and its effects on the pile response under loading are studied. The data show a marked influence of soil partial saturation on the pile response, both under working loads and ultimate loads. In particular, under working loads, the displacement of the head of the pile is appreciably lower than that measured under saturated conditions.
\end{abstract}

\section{Introduction}

Pile foundations are frequently used in geotechnical engineering problems to support a combination of axial forces, lateral forces and concentrated moment. In some applications, the lateral component of the external forces can be crucial in pile design, for example tall structures under wind load, bridge abutments, earth-retaining structures, wind turbines.

The kinematics of pile foundations under lateral loading typically involves a significant soil volume close to the surface (several diameters of depth below the ground level). The wide literature on this topic, including experimental, analytical and numerical studies, shows that the response of flexible piles is largely influenced by relative pile-soil stiffness ratio, whereas for short and rigid piles, the response is affected by both stiffness and slenderness ratio ([1, 2, 3, 4]). Moreover, the non-linear soil behaviour strongly influences the main design parameters of the pile such as head displacement, maximum bending moment, and critical length ([5]). In many applications, the significant volume close to the ground surface can be above the water table, and frequently is partially saturated.

To date, the effects of suction and saturation degree on the mechanical behaviour of soils have been widely investigated by laboratory and theoretical studies. Gens [6] presented a compendium of current knowledge including some case histories of typical geotechnical problems involving unsaturated soils. In recent years, some studies have been published on the influence of partial saturation in engineering problems such as bearing capacity of shallow and deep foundations ([7, 8]). However, current practice for design often neglects the potential benefits of soil partial saturation in soilstructure interaction problems.

Physical centrifuge modelling represents a valid methodology to experimentally investigate soil-structure interaction problems. The small scale model is linked to the full scale prototype, following scaling laws $([9,10])$. When the scale of the model is $1 / N$, the model has to be subjected to a centrifuge $g$-level of $N$. Traditionally, studies have been conducted on fully saturated or completely dry soil models. Recently, unsaturated soil behaviour has been explored by centrifuge modelling ([11, 12, 13]). Scaling laws for unsaturated soils have been experimentally investigated by different authors under various $g$-levels and for different soils. Depountis et al. [14] investigated the capillary rise in fine sands founding small deviations from the theoretical scale factor for $N>50 \mathrm{~g}$. The authors argued that this was likely to be due to either the instrumentation used or some gravity effect on the water menisci. Conversely, Knight et al. [15] showed that the scaling factor for the capillary rise was the same at $50 \mathrm{~g}$ and $100 \mathrm{~g}$. Caicedo et al. [16] verified the scaling laws for time and lengths in unsaturated expansive clays at 100, 200 and $400 \mathrm{~g}$, finding a good agreement with the theoretical values. Details of the analytical formulations can be found in Soranzo et al. [13] and other studies [17, 18]. The scaling factors adopted in this study are listed in Table 1.

The paper presents the main findings of an experimental study focused on the influence of partial saturation on the behaviour of laterally loaded piles. The

\footnotetext{
*Corresponding author:leonardo.lalicata@city.ac.uk
} 
aim of the experiment is to study the response of a single free-head pile, subjected to a combination of lateral loading and bending moment, under different hydraulic conditions. The centrifuge tests $(N=100 \times g)$ were carried out using the IFSTTAR centrifuge facilities of Nantes (France) in the framework of the GEOTRANSALPPILE-UNSAT agreement.

Table 1. Scaling laws for centrifuge modelling.

\begin{tabular}{|c|c|}
\hline Parameter & $\begin{array}{c}\text { Scaling law } \\
\text { model/prototype }\end{array}$ \\
\hline Length & $1 / \mathrm{N}$ \\
\hline Density & 1 \\
\hline Unit weight & $\mathrm{N}$ \\
\hline Stress & 1 \\
\hline Strain & $1 / \mathrm{N}^{2}$ \\
\hline Force & $1 / \mathrm{N}^{3}$ \\
\hline Bending moment & $1 / \mathrm{N}$ \\
\hline Seepage velocity & $1 / \mathrm{N}^{2}$ \\
\hline Consolidation time & $1 / \mathrm{N}$ \\
\hline Capillary rise & \\
\hline
\end{tabular}

\section{Experimental design and procedure}

An experimental study was carried out in the geotechnical centrifuge [19], which focused on the response of a single pile under lateral loading with different positions of the water table in partially saturated soils. In addition, the research offered an insight into the effect of the water table rising on the behaviour of the pile. The soil model was statically compacted to the desired density under a press in the laboratory.
In total four centrifuge tests were undertaken, varying both the elevation of the water table, $z_{w}$, and the initial void ratio of the soil, $e_{0}$. In the two tests where the water table was $70 \mathrm{~mm}$ from the ground level the pile was loaded until a lateral displacement, $y$, of $30-40 \%$ of the diameter, $D$, was reached. In the following step, the water table level was raised quickly to ground level keeping the load constant. For the sake of comparison, two additional tests were conducted up to soil failure in fully saturated condition $\left(z_{w}=0\right)$ on soil samples prepared at the same void ratio of the main tests. Measurements of pile displacements, lateral load and bending moments were recorded.

In order to reduce the as compacted suction, the samples were subjected to an imbibition process at $1 \mathrm{x} g$, connecting the bottom of the model with the water reservoir.

Before pile loading, equalisation of pore pressures in the soil was allowed. The load was applied with a very slow displacement rate to avoid the creation of excess pore pressures.

The water table position in the different tests is listed in Table 2 together with soil condition after compaction. In the table, $w$ and $S r_{0}$ are the water content and the degree of saturation while $\sigma_{v c}$ is the compaction stress.

Table 2. Testing programme.

\begin{tabular}{|c|c|c|c|c|c|}
\hline $\begin{array}{c}\text { Test } \\
\text { ID }\end{array}$ & $\boldsymbol{e}_{\boldsymbol{0}}$ & $\begin{array}{c}\boldsymbol{z}_{\boldsymbol{w}} \\
(\mathbf{m m})\end{array}$ & $\boldsymbol{w}_{\boldsymbol{0}}$ & $\begin{array}{c}\boldsymbol{\sigma}_{\boldsymbol{v c}} \\
(\mathbf{k P a})\end{array}$ & $\boldsymbol{S r}_{\boldsymbol{0}}$ \\
\hline T 05 & 0.93 & 0 & 15.03 & 580 & 42.02 \\
\hline T 06 & 0.93 & 70 & 14.67 & 559 & 42.01 \\
\hline T 08 & 0.75 & 70 & 14.72 & 1395 & 51.03 \\
\hline T 09 & 0.75 & 0 & 14.72 & 1395 & 51.03 \\
\hline
\end{tabular}

\subsection{Model apparatus}

The soil models were statically compacted, under onedimensional condition, in a rigid cylindrical container of $300 \mathrm{~mm}$ in diameter. A $10 \mathrm{~mm}$ thick sand layer,

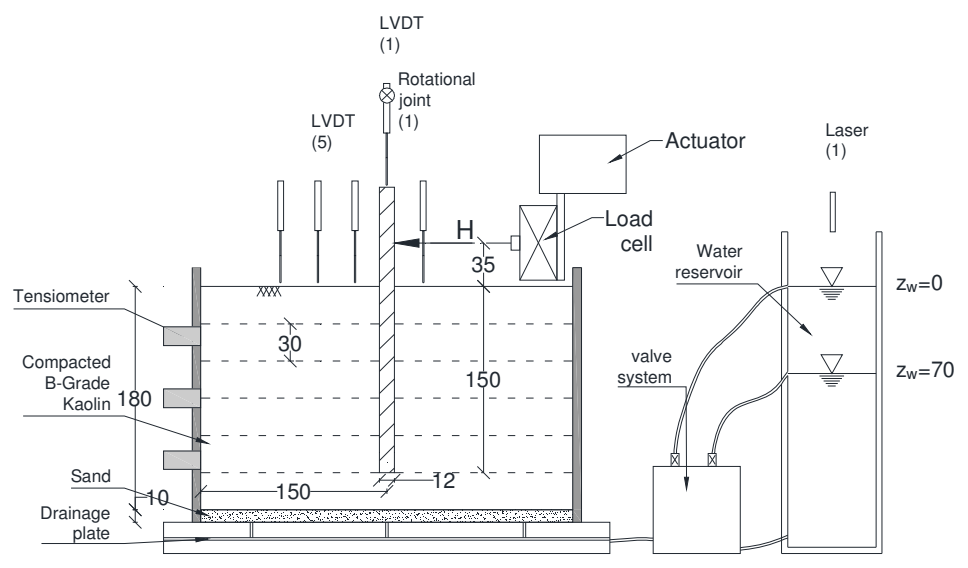

Fig. 1. Experimental set up. 
surrounded by geotextile, allowed drainage at the bottom of the model. A $2 \mathrm{~mm}$ thick plastic sheet lined the sides to reduce skin friction during model preparation and during the test. A plastic film covering the soil surface prevented water evaporation in the upper part of the model. The pile was bored in the centre of the model, at $1 \mathrm{x} g$, by means of a manual screwing system. The screw was mounted into a rigid frame to maintain position and verticality.

The bottom of the model was connected to a water reservoir, the level of which was governed by an electropneumatic valve system remotely controlled by the operator from the centrifuge control room. A laser sensor measured the water height in the tank.

The model was extensively instrumented in order to follow both the equalization phases and pile loading (Fig. 1). Five LVDT sensors measured soil settlements, three tensiometers, installed on the side of the container, measured the pore water pressure (negative and positive) in the soil. The lateral load was applied at $35 \mathrm{~mm}$ from ground level by a hydraulic actuator. The loading phase was displacement-controlled $(v=0.003 \mathrm{~mm} / \mathrm{s}$ at model scale), and a load cell measured the lateral load. One LVDT built in on a rotational joint gives the pile's vertical displacement and rotation.

At the end of each test, undisturbed specimen were sampled to obtain the water content and void ratio distribution with depth.

\subsection{The pile}

The model pile (scale 1/100) is a close-ended aluminium tube (external diameter $D=12 \mathrm{~mm}$, thickness $t=1 \mathrm{~mm}$ ) embedded into the soil for $150 \mathrm{~mm}$. The pile was instrumented with 10 pairs of strain gauges arranged every $15 \mathrm{~mm}$, providing the bending moment profile along the pile length. At prototype scale, the model represents a full circular pile of $1.2 \mathrm{~m}$ diameter, $15 \mathrm{~m}$ embedded length with a bending stiffness of $3.9 \mathrm{GN} \cdot \mathrm{m}^{2}$, subjected to a lateral load applied at $3.5 \mathrm{~m}$ from the ground surface. The combination of the soil stiffness, the high bending stiffness and relatively small slenderness ratio $(L / D=12.5)$ led to essentially rigid behaviour of the pile.

\subsection{Soil properties and model preparation}

The soil used in the centrifuge tests is a low plasticity $(I P=14 \%)$ commercial clayey silt called B-Grade kaolin. A complete hydro-mechanical characterisation was conducted in the geotechnical laboratory using standard apparatus for unsaturated and saturated soils. Major details can be found in [19] and [20]. Here, only the main wetting soil water retention curves (SWRCs) are reported in Fig. 2. The SWRCs were obtained, for the two different void ratios of 0.93 and 0.75 , using a suction controlled oedometer. In the suction range experimentally studied, the data exhibit a marked influence of porosity in the retention behaviour. In fact, as porosity decreases, air entry value increases and the slope of the transition zone reduces in the $S r-s$ plane.

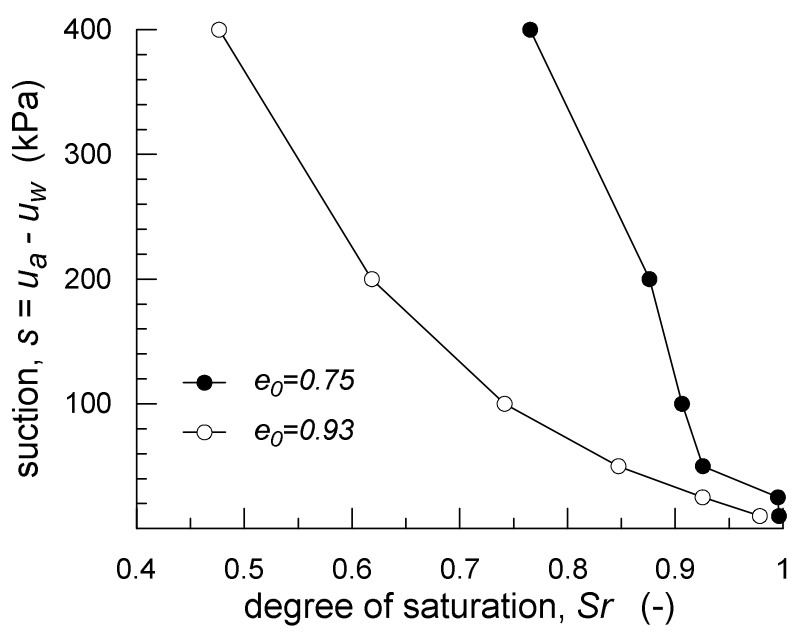

Fig. 2. Main wetting soil water retention curves (SWRCs) for B-grade kaolin.

Samples were statically compacted on the dry side of the optimum Proctor curve (optimum water content $w_{\text {opt }}$ and void ratio $e_{o p t}$ equal to $21 \%$ and 0.74 , respectively) at the same water content $(w=15 \%)$ and two different voids ratio (0.93 and 0.75$)$. To achieve a good homogeneity, the soil model was compacted in six layers of final height $30 \mathrm{~mm}$. The reasonable homogeneity of the distribution of vertical compaction stresses, Fig. 3, and the good repeatability of the results in the different tests confirm the validity of the procedure used. The compaction stress increases with dry density from a mean value of $500 \mathrm{kPa}$ for the soft soil $\left(e_{0}=0.93\right)$ to $1400 \mathrm{kPa}$ for the hard soil $\left(e_{0}=0.75\right)$.

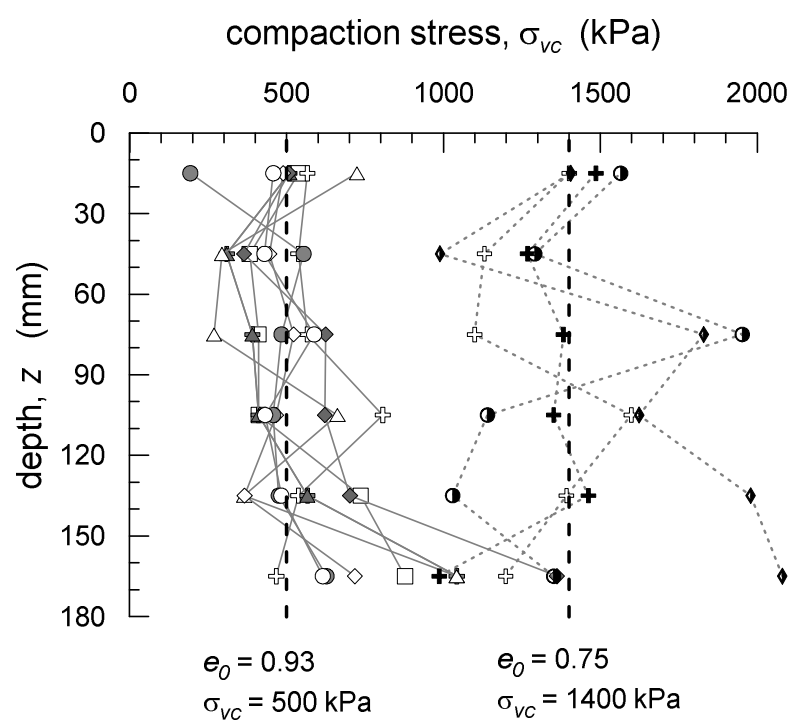

Fig. 3. Compaction vertical stresses.

\section{Results and discussion}

A typical evolution with time of the main variables of the test (T 08) is shown in Fig. 4. During the imbibition, the suction in the model reduced (Fig. 4 (c)) and the model globally swelled (Fig. 4 (b)). The centrifuge test 
started after 1200 minutes (approximately): the model was spinning at $100 \mathrm{xg}$ and the height of the water column in the reservoir was kept constant $70 \mathrm{~mm}$ below the ground surface. The model was allowed to equalise for about 4 hours before applying the lateral load to the pile (Fig. 4 (d) and (e)).

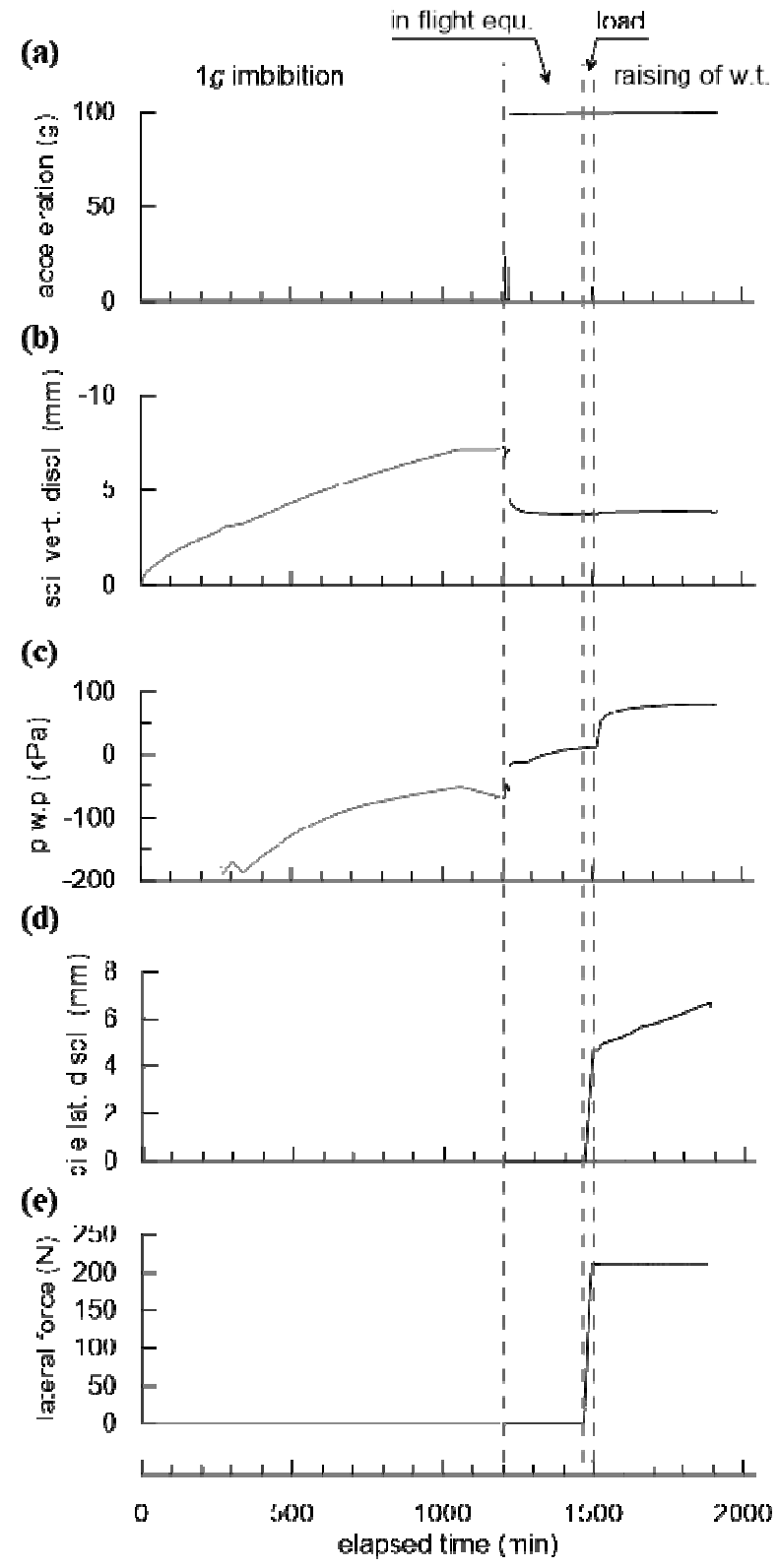

Fig. 4. Timeline of a test.

The volumetric behaviour of the soil during the phases preceding the loading of the pile is mainly a function of the compaction conditions (void ratio, water content and initial effective stress), the permeability of the soil and its dependence on the degree of saturation. A study on the effects of the imbibition at $1 \times \mathrm{x}$ and of the in-flight equalisation on the soil behaviour and its consequences on the pile response are presented in [20].

Once the loading of the pile was completed, the actuator was switched from displacement control to loading control and the pore pressure at the bottom of the model was quickly increased from 120 to $190 \mathrm{kPa}$, to simulate the water table rising from $70 \mathrm{~mm}$ depth to 0 $\mathrm{mm}$. The model was left in equalisation for the remaining time of the test.

For the sake of brevity, only the results of the loading stage and the increasing of the water table are presented in this paper. The results refer to the higher void ratio only as the effect of soil partial saturation are more pronounced in this case. The complete results of the experimental program are detailed in [19].

The influence of partial saturation on the loaddisplacement relationship is shown in Fig. 5, at model scale. Displacements are depicted in normalised form, $y / D$, where the lateral displacement $y$ is the displacement at the load application point. In saturated soil condition ( $\mathrm{T}$ 05), the load-displacement relationship exhibits a nonlinear behaviour even at low values of displacement, indicating that the soil develops significant plastic strains even at very low load level ([5]).

In unsaturated soil conditions (T 06), the pile shows a significant increase in the initial stiffness. Moreover, the load-displacement relationship appears to be linear up to $y / D=0.1$, corresponding to the threshold value currently used in the practice to guarantee the serviceability of the overlaying structure. This indicates that only a negligible amount of soil yielding occurs even at relatively large displacement values.

The experimental data can be adequately fitted by means of a hyperbolic function:

$$
H=\frac{y}{\left(\frac{1}{K}+\frac{1}{H_{u}} y\right)}
$$

where $K(\mathrm{~N} / \mathrm{mm})$ is the initial stiffness and $H_{u}(\mathrm{~N})$ is the asymptotic load, the interpolation function is represented by continuous lines in Fig. 5. Passing from saturated to unsaturated soil condition, the initial stiffness increases from 15 to $62 \mathrm{~N} / \mathrm{mm}(+300 \%)$ and the predicted ultimate load rises from 90 to $290 \mathrm{~N}(+220 \%)$. Therefore, neglecting the partial saturation of the soil leads to a very significant underestimation of the lateral capacity of the pile.

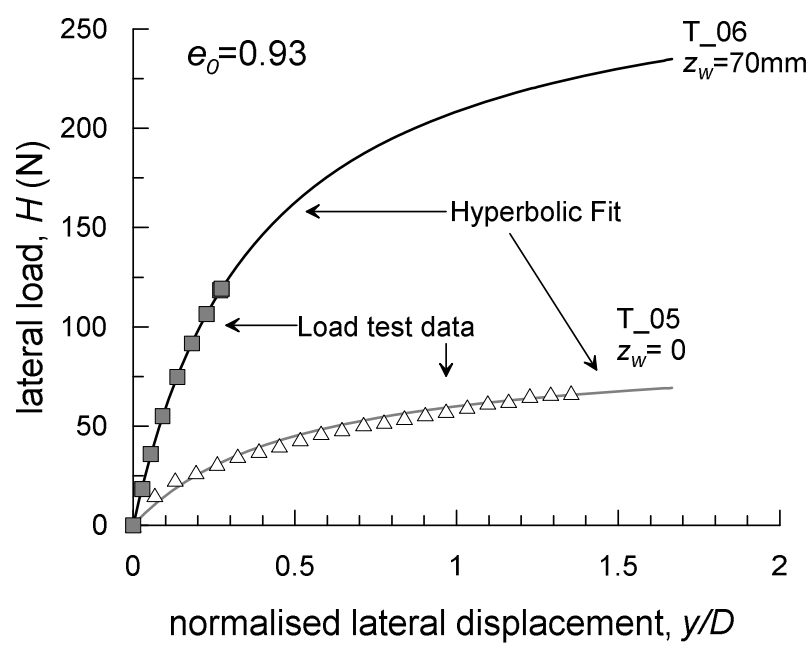

Fig. 5. Load-displacement relationships. 
After the results of small scale tests, [21] proposed a simplified distribution of the ultimate soil pressure along the pile based on the actual kinematics of a rigid pile. The solution was derived for rigid piles in cohesionless soils. Hence it may be applied to test T 05 where $z_{w}=0$. Following [21], the ultimate pressure varies linearly from 0 at the ground surface to a maximum at $z=0.6$ times the elevation of the rotation point, $x$. Below the maximum, the pressure is 0 at the rotation point then the net pressure changes sign and attains the mimimum value at the pile toe (1.7 times the maximum positive pressure). For this test, The method predicts the position of the rotation point at $111 \mathrm{~mm}$ from the ground level and an ultimate load $H_{u}$ of $82.6 \mathrm{~N}$.

According to the theorical methods available in the literature, it is possible to use the pressure distribution derived from retaining wall theory, accounting, approximately, for the three dimensional effects with a shape factor:

$$
p_{z}=s K_{p} \sigma_{v}^{\prime}(z)
$$

Where $s$ is the shape factor (here taken as 3 ), $K_{p}$ is Rankine's passive earth pressure coefficient and $\sigma_{v}^{\prime}(z)$ is Terzaghi's vertical effective stress. The theoretical soil peak pressure distribution for the saturated soil is shown in Fig. 6 together with the distribution obtained in unsaturated soil condition (T 06) at $H=120 \mathrm{~N}$ (before the raising of the water table). The latter is obtained by double derivation of the bending moment distribution and dividing the resulting reaction for the diameter of the pile.

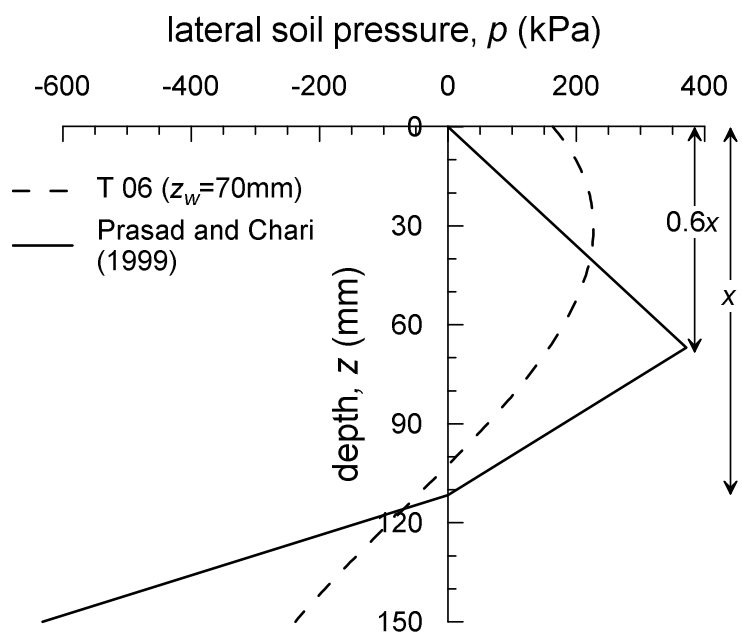

Fig. 6. Lateral soil pressure.

The two distributions are very different. In particular, under unsaturated conditions, the soil pressure is very high at ground level and increase up to $30 \mathrm{~mm}$ of depth. Hence, it gradually reduces moving downward. Furthermore, the centre of rotation of the pile $(z=100 \mathrm{~m})$ moves toward the ground level compared to the saturated (theoretical) case.

It must be pointed out that the two distribution are not directly comparable in quantitative terms because, for the unsaturated case, the $H / H_{u}$ ratio is 0.412 well below failure conditions. It is not worth proposing an alternative distribution of peak soil pressure under unsaturated soil condition, due to the lack of experimental evidence. Additional experimental and/or numerical results are needed to define it.

In unsaturated soil condition, the effective stress is not zero at the ground level and equal to the product $S r \cdot u_{w}$. This gives rise to not negligible stiffness moduli and shear strengths even at the shallower depths. In the case of a pile under lateral loading, the major interaction occurs in this superficial volume of soil. Therefore, the presence of a stiff and resistant shallow layer, induced by the partial saturation, strongly changes the soil pressure distribution along the pile (Fig. 6) and hence the overall pile behaviour (Fig. 5).

In test $\mathrm{T} 06$, where the water table was $70 \mathrm{~mm}$ below the ground level, the loading stage stops at $120 \mathrm{~N}$, and then the water table is rised to ground level. The analysis of the pore pressure evolution indicates that the stationary condition has not been reached, Fig. 7 (a).

Suction decrease, due to imbibition, led to a reduction of mean effective stress and of the preconsolidation pressure (where collapse for saturation occurs), as well as the soil stiffness and strength. As a result, the pile head displacement increased (Fig. 7 (b)). It is interesting to note that, even if no stabilization occurs, the slope of the pore pressure curves gradually reduces, while the increment of lateral displacement keeps growing.

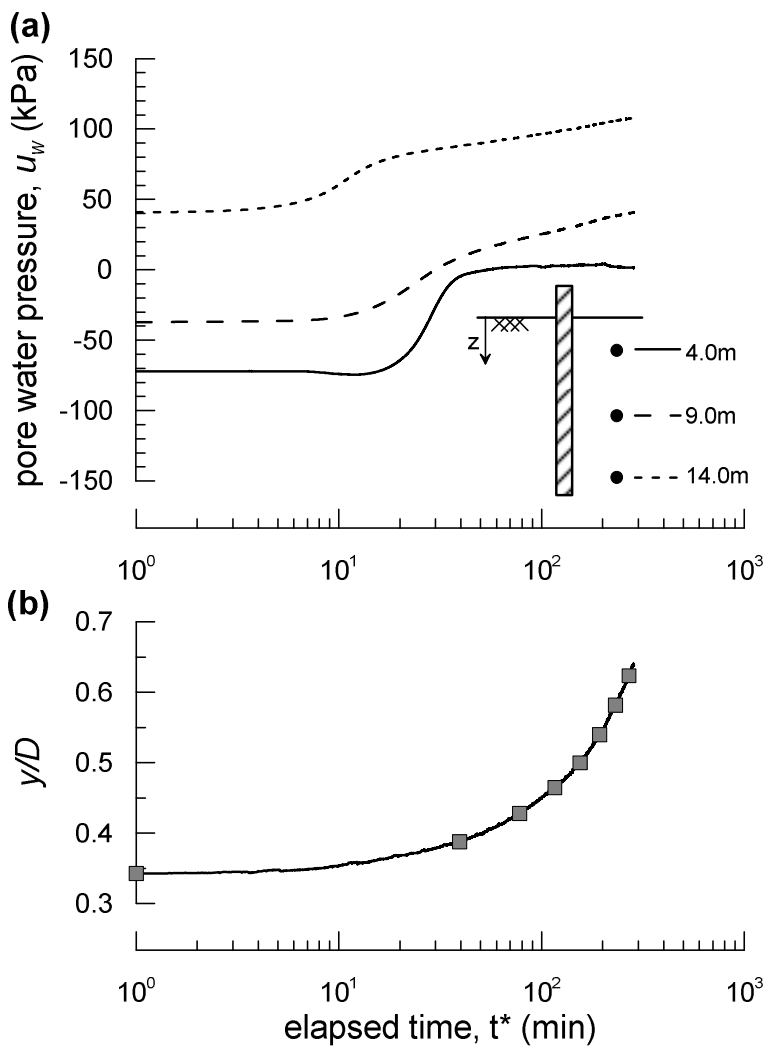

Fig. 7. Evolution with time during water table rising of tests: (a) pore pressure at different elevations, (b) lateral displacement.

During saturation, the strength reduction in the upper part carried a reduction of soil pressure against the pile in the first metres of depth from ground level and an 
increase in the final metres (Fig. 8). Observing the bending moment profiles prior and post water table rising (Fig. 8), it can be seen that there is a general increment of the moment below the position of the maximum bending moment (from 6 to $15 \mathrm{~m}$ of depth). Given that the pile undergoes a rigid body motion during saturation, the maximum bending moment variation is less than $10 \%$.

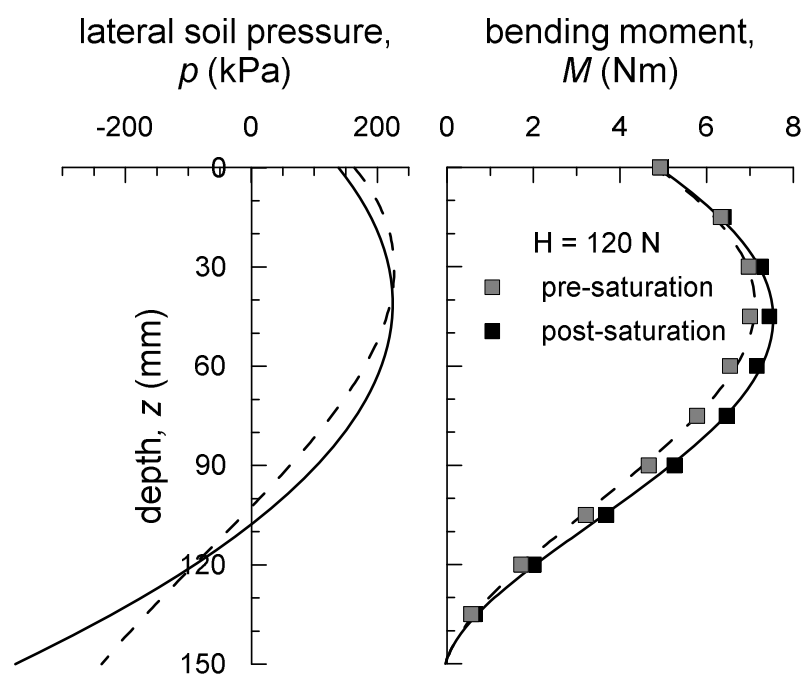

Fig. 8. Peak soil stresses and bending moment distribution before and after saturation.

\section{Conclusions}

The research highlights the importance of soil partial saturation on the behaviour of piles under lateral loading. In the present work, selected aspects of geotechnical centrifuge tests are presented and discussed. The soil models used in the experimentation were statically compacted on the dry side of the Proctor curve. The better performance of the pile in unsaturated soil conditions is linked to the different distribution of the pressures against the pile. In fact, the presence of high effective stresses and the preconsolidation pressures in the shallower layer of the soil allows this soil portion to sustain the majority of the interaction with the pile.

The results refer to an almost rigid pile and one specific position of the water table. Additional tests are required to investigate the effect of partial saturation varying the soil-pile relative stiffness, the slenderness ratio and the elevation of the water table. During saturation, due to the combination of excessive load level and strong variation of water table level, the system tends to soil collapse with a close to rigid body motion.

\section{References}

1. M. Budhu, T.G. Davies. Can. Geot. J. 24, 2, 289296 (1987). doi:10.1139/t87-034.

2. M.F. Randolph. 1981. Géotechnique, 31, 2, 247-259 (1981). doi:10.1680/geot.1981.31.2.247.
3. R: Di Laora, E. Rovithis, E. J. of Geot. and Geoenv. Eng., 141, 4, (2015). doi: 10.1061/(ASCE)GT.19435606.0001270 .

4. R. Krishnan, G. Gazetas, A. Velez, A. Géotechnique, 33, 3, 307 - 325 (1983). doi: 10.1680/geot.1983-33.3.307.

5. G. Russo. Soils and Foundation, 56, 1, 33-43 (2016). doi:10.1016/j.sandf.2016.01.003.

6. Gens. Géotechnique, 60, 1, 3-64 (2010). doi:10.1680/geot.9.P.109.

7. K. Georgiadis, D.M. Potts, L. Zradvkovic, L. Géotechnique, 53, 1, 11-25 (2003).

8. S.K. Vanapalli. Unsaturated Soils - Experimental Studies in Unsaturated Soils and Expansive Soils. (CRC Press, Newcastle, 2009).

9. J.F: Corté J.F. 1989. Model testing-Geotechnical model tests. Proc. of XII ICSMFE, (Rio de Janerio, Balkema, Rotterdam 1989).

10. A.N. Schofield. Géotechnique 30, 1, 229-267 (1980). doi:10.1680/geot.1980.30.3.227.

11. F. Casini, J. Muñoz, S. Lorenco, L. Thorel, J. Vaunat, P. Delage, G. Gallipoli. In Between theory and practice in unsaturated soil mechanics (eds A. Tarantino and C. Mancuso, Rotterdam: Millpress, 2009).

12. L. Thorel, V. Ferber, B. Caicedo, I. Khokhar. Géotechnique, 61, 5, 409-420 (2011). doi:10.1680/geot.10.P.029.

13. E. Soranzo, R. Tamagnini, W. Wu, W. Géotechnique, 65, 6, 454-467 (2015). doi:10.1680/geot.14.P.123.

14. N. Depountis, M.C.R Davies, C. Harris, S. Burkhart, L. Thorel, A. Rezzoug, D. Konig, C. Merrifield, W.H. Craig, W.H. Eng. Geology, 60, 1-4, 95-106 (2001).

15. M.A. Knight, A.B. Cole, R.J. Mitchell. Proc of Int. Symp. on Physical Modelling and Testing in Environmental Geotechnics (eds J. Garnier, L. Thorel, E. Haza, Paris: LCPC, 2000).

16. B. Caicedo, C. Medina, A. Cacique. 2006. Proc. of ICPMG06, (Hong Kong, Balkema, Rotterdam, 2006).

17. B. Caicedo, L. Thorel. J. of Geoeng. Sc., 2, 1-2, 83103 (2014). doi:10.3233/JGS-130013.

18. M. Mirshekari, M. Ghayoomi, A. Borghei. Geot Test. J., 45, 6, 979-997 (2018). doi:10.1520/GTJ20170120

19. L.M. Lalicata, A. Desideri, F. Casini, L. Thorel. Can. Geot. J. (2018), doi.:10.1139/cgj-2018-0322.

20. G. M. Rotisciani, L.M. Lalicata, A. Desideri, F. Casini. Proc of $4^{\text {th }}$ European Conf. on Unsaturated Soils (2020).

21. Y.V.S.N. Prasad, T.R. Chari. Soil and Found., 39, 2, 21-29 (1999). 